University of Wollongong

Research Online

Faculty of Science, Medicine and Health -

Papers: part A

Faculty of Science, Medicine and Health

$1-1-2014$

Critical cartography and the use of new technologies for conserving the Australian coastline: a case study from Lord Howe Island

Sarah Hamylton

University of Wollongong, shamylto@uow.edu.au

Follow this and additional works at: https://ro.uow.edu.au/smhpapers

Part of the Medicine and Health Sciences Commons, and the Social and Behavioral Sciences

Commons

Recommended Citation

Hamylton, Sarah, "Critical cartography and the use of new technologies for conserving the Australian coastline: a case study from Lord Howe Island" (2014). Faculty of Science, Medicine and Health - Papers: part A. 1467.

https://ro.uow.edu.au/smhpapers/1467

Research Online is the open access institutional repository for the University of Wollongong. For further information contact the UOW Library: research-pubs@uow.edu.au 


\title{
Critical cartography and the use of new technologies for conserving the Australian coastline: a case study from Lord Howe Island
}

\author{
Abstract \\ Maps exert power. In this paper I explore the power of maps in relation to the technical methods \\ employed and the political context of their production. The internal power of maps is realised in the \\ actions taken by cartographers themselves when making maps, while the external power of maps is both \\ realised by the patrons of cartography and wielded through the use of cartographic products as agents \\ for natural resource management, in particular for defining conservation strategies. An Australian case \\ study of coastal mapping is used to examine the methods employed and motivation behind map \\ production through a series of recent remote sensing initiatives to map Lord Howe Island, New South \\ Wales. Through this case study I explore the subjectivities associated with the placement of boundaries \\ in the scientific practice of cartography. I argue that a new epistemological reading of maps is necessary, \\ as sources of information on socio-politically constructed worlds as much as the phenomenological \\ world of objects. Such a reading is particularly important given recent advances in technologies, such as \\ remote sensing, that are increasingly used to inform coastal management, and which propagate in \\ profound new ways the power of maps.

\section{Keywords} \\ GeoQuest

\section{Disciplines} \\ Medicine and Health Sciences | Social and Behavioral Sciences

\section{Publication Details} \\ Hamylton, S. (2014). Critical cartography and the use of new technologies for conserving the Australian \\ coastline: a case study from Lord Howe Island. Geographical Research, 52 (1), 65-73.
}




\section{Critical cartography and the use of new technologies for conserving the}

Australian coastline: A case study from Lord Howe Island

\section{SARAH HAMYLTON}

School of Earth and Environmental Sciences, University of Wollongong, Wollongong, NSW 2522, Australia.Email: shamylto@uow.edu.au

\section{$\underline{\text { Abstract }}$}

Maps exert power. In this paper I explore the power of maps in relation to the technical methods employed and the political context of their production. The internal power of maps is realised in the actions taken by cartographers themselves when making maps, while the external power of maps is both realised by the patrons of cartography and wielded through the use of cartographic products as agents for natural resource management, in particular for defining conservation strategies. An Australian case study of coastal mapping is used to examine the methods employed and motivation behind map production through a series of recent remote sensing initiatives to map Lord Howe Island, New South Wales. Through this case study I explore the subjectivities associated with the placement of boundaries in the scientific practice of cartography. I argue that a new epistemological reading of maps is necessary: as sources of information on socio-politically constructed worlds as much as the phenomenological world of objects. Such a reading is particularly important given recent advances in technologies such as remote sensing that are increasingly used to inform coastal management, and which propagate in profound new ways the power of maps.

Keywords: Critical cartography, coastal mapping, GIS, remote sensing 


\section{The use of maps for natural resource management}

Two "edges" are used in this paper to explore the power of maps as drivers of our decision making in the management of natural resources: the edge of discipline and the cutting edge. These edges provide a framework for applying to coastal research the rapidly growing discipline of critical cartography, which seeks to determine how, and in what ways, maps have and exercise power (Wood and Fels 1992; Harley 1996; Harley 1997; Crampton 2001; Pickles 2006; Dodge, Kitchin and Perkins, 2011). In this paper I connect critical cartography and recent practices in biophysical research, specifically new technologies such as remote sensing, to critically examine the power of maps in defining conservation strategies. My intention is to highlight the subjectivities associated with cartographic campaigns, both in relation to the motivations of these campaigns and their placement of boundaries in the scientific practice of cartography.

The disciplinary overlap between critiques of power and environmental thinking and practice is becoming an increasingly productive site of geographical scholarship. In relation to contemporary conservation strategies, for example, and particularly the establishment of national parks, the influence of colonial thinking on conservation practice is under increased scrutiny (Adams and Mulligan 2003). Maps have become powerful communication tools in relation to the division and allocation of space for conservation, for example, in the establishment of protected areas. In the Australian case, state and federal government mapping initiatives accompanied the designation of numerous national parks across the late twentieth century, such as the Great Barrier Reef, South-West Tasmania, the Alps, Fraser Island, Myall Lakes or the Tarkine (Figgis and Cameron 2003). For Figgis (2003) and Cameron (2003), a placeresponsive culture has arisen from the combination of a distinctive landscape, flora and fauna alongside a growing importance of a political sense of place. Particularly in Australia, it is therefore necessary to conduct geographical research with an awareness of the political nature of this pursuit and a self-reflexivity of our position (Jacobs 1996; Howitt, 2002).

Discussing the power of maps in the context of Australian geography is timely and urgent, because, in spite of the apparent power of the map as a form of communication, and the increasing penetration of spatial and locational technologies 
into everyday life (Gibson et al 2010), many national and international University cartographic units have experienced recent closure or funding cuts. It appears that traditional cartography is slowly being superseded by geospatial technologies, supported by recent developments in GIS, GPS and remote sensing, which collectively offer exciting prospects for mapping, monitoring and modelling real world phenomena. Crampton (2010) notes that the development of widely available and free mapping applications such as Google Earth is taking the practice of map making out of the hands of experts and making it available to anyone with a home computer and broadband internet connection. Yet at the same time, methods and technologies for geospatial analysis and surveying have become ever more sophisticated - heightening the sense in which technical expertise and professional qualifications overlay the traditional power of mapping as cartography. I wish to explore the challenges and opportunities such developments pose to geographers.

\section{The Edges of Disciplines: A framework for interrogating the power of maps}

The study of cartographic power draws on perspectives that traditionally align with both human and physical geography. On the one hand, a positivist stance holds that the reality of objects in the world can be expressed in mathematical terms; that systematic observation and measurement offer the only route to a cartographic truth that can be independently verified. Thus, with the application of science, the world can be categorised into ever more precise and accurate units, aided by the advent of geospatial technologies to the point where, to employ a phrase adopted by philosopher Richard Rorty, we can construct "mirrors of nature” (Rorty 1979). On the other hand, a more critical stance may read a map as a cultural portrayal, a mechanism for defining social relationships, sustaining social rules, and strengthening social values (Crampton 2001). A critical approach seeks to examine the assumptions of a field of knowledge:

“A critique does not consist in saying things aren't good the way they are. In consists in seeing on what type of assumptions, of familiar notions, of established, unexamined ways of thinking the accepted practices are based" (Foucault 2000; pg 456) 
The power that maps have to shape our understanding of place has remained a central theme to the field of critical GIS. Couclelis (2003) suggests that the role of GIS in the synthesis of geographic knowledge is underpinned by data, method and products that are also subject to principles of abduction, deduction and nonmonotonic reasoning, which introduce logical uncertainty that is inherent in many forms of artificial intelligence. Sui (2001; 2004) identifies both physical and logical limits of computation that have emerged through our continuing efforts to understand nature from a digital perspective (Tobler, 1959). Social theorists have used structuralist, interpretative and feminist approaches to elaborated on these limitations in a geographical context (Sheppard, 1993). Structuralist approaches use theoretical analysis to emphasise the influence of unobserved or unobservable structures, whose operation may be obscured by empirical associations. Interpretative approaches emphasise the difficulty of both determining the significant aspects of geographical phenomena and placing a definitive interpretation on them, while feminist approaches regard experimental and deductive practices of scientists as a manifestation of valued male behaviour, rather than a superior approach to understanding (Schuurman and Pratt, 2010). Sui (2001) suggests that to move toward an ultimate goal of using GIS to develop our understanding of how nature works and how humans can organise their activities on the earth's surface, it is necessary to develop GIScience along two seemingly contradictory lines. On the one hand we must refine our ability to make phenomena computable, while simultaneously recognising the fundamental limits of computation and building dialogues with a variety of different scholarly traditions.

A critical GIS perspective views maps as texts to be read with an awareness of the contexts in which they were written. By positioning maps within their societal context, a richer interpretation of their role in furthering our understanding of place can be provided, one that extends to an exploration of how contemporary digital cartography, remote sensing and GIS are used by society to inform natural resource management. To acknowledge both of these perspectives, I wish to adopt a dual framework suggested by Brian Harley, who was both a cartographer and critical scholar of maps who drew on the work of poststructuralist thinkers such as Michel Foucault and Jacques Derrida to theorise their power (Harley 1989). Harley examined the power of maps from a positivist and a poststructuralist perspective, drawing on the internal and the external dimensions of their power. External power is realised by the 
patrons of cartography and wielded through the use of cartographic products. Internal power, Harley argues, is largely determined by the actions taken by cartographers themselves when making maps. Cartographic process is therefore the key to this internal power, which Harley defines as:

"the way maps are compiled and the categories of information selected; the way they are generalized, a set of rules for the abstraction of the landscape; the way the elements in the landscape are formed into hierarchies; and the way various rhetorical styles that also reproduce power are employed to represent the landscape. To catalog the world is to appropriate it, so that all these technical processes represent acts of control over its image which extend beyond the professed uses of cartography.”(Harley, 1989; pg 13)

Such a definition can be applied broadly to anything that determines the knowledge of the world made available to people through maps, including the entire discourse of positivism that underpins cartography and the perspectives brought to bear by the field of critical GIS. This framework provides us with a useful means to interrogate how, and in what ways, maps have and exercise power.

\section{The use of cartography to inform management of Lord Howe Island marine reserve}

"Some persons condemn me for having endeavored to conciliate His Majesty's rebellious subjects, by taking every means to prevent the destruction of the country... I acted in that particular for the benefit of the King's service" (Sir William Howe, 5th Viscount Howe, 1779 in Fischer; pg 66)

This case study summarises an exercise undertaken at the University of Wollongong in which 15 geospatial analysts used a collection of identical datasets from Lord Howe island to answer two common coastal management questions. The widely varying responses highlight the inherent subjectivities associated with decisionmaking in the process of geospatial analysis. The intention of this case study is not to provide a complete and comprehensive account of the multi-layered ways in which cartographic products are powerful; rather, to show how the power of maps can be 
propagated through new technologies and practices by critiquing a simple mapping exercise applied to facilitate the conservation of Lord Howe Island, New South Wales. As the above quote suggests that perhaps Lord Howe himself would have sympathised with some of the sentiments of conservation, assuming they aligned well with the wishes of the King.

Lord Howe Island is a $1463 \mathrm{~km}^{2}$ continental island in the Tasman Sea, approximately $600 \mathrm{~km}$ east of Port Macquarie on the New South Wales Coastline. The island sits on a shallow (<70 m water depth) shelf that supports relic and modern reef platforms, as well as basin and channel areas that provide habitat for marine biodiversity, including 448 subtropical and temperate fish species (Francis 1993). In 1982 the island and surrounding shelf were listed as a World Heritage Site because of the unique coral community association at the southern latitudinal limit of their distribution and the high degree of endemism displayed by both marine flora and faunal species (Harriott et al 1995; UNESCO 2011), as well as the importance of this site as a potential substrate for southward reef expansion in response to warmer sea surface temperatures (Woodroffe et al. 2010).

Conducting in-situ surveys of the remote marine biodiversity of Lord Howe Island represents a costly and logistical challenge because it is spread across $>3000 \mathrm{~km}^{2}$, yet there is a substantial requirement for information on the biophysical character of these islands and the terrestrial and marine biodiversity they support. Several studies have attempted to map and model the biodiversity of Lord Howe Island, drawing on geospatial technology as it has developed over the last 50 years to extrapolate information from localised field surveys to larger, landscape scales. These include surveys of the biological and geological environments of the submarine plateau (Harris 2011; Nichol et al. 2011) and the development of models linking the physical environment and biological assemblages (e.g. coral habitat and reef fish diversity) extending around the flank of the Lord Howe Rise (Lindsay et al. 2008; Anderson et al. 2011). These activities exemplify the increased refinement of maps depicting the marine biodiversity of these islands and the development of more complex uses of remote sensing datasets to derive information on the marine biodiversity supported by them, which draw on state of the art remote sensing technology and illustrate a cartographic cutting edge. 
In 2000, the Lord Howe Island Marine Park was established across commonwealth waters (3 nautical miles to 12 nautical miles from the coastline) under the management of the Federal Government in collaboration with the NSW Marine Parks Authority. The stated objective of the park was as follows: “ to protect the seamount system and its conservation values associated with marine biodiversity, habitats and ecological processes. Such protection will also ensure the long-term maintenance of the high quality marine environment important to the Island's tourism industry, as well as the traditions and lifestyle of the local community.” In 2002, the Management Plan for the Lord Howe Island Marine Park further divided the commonwealth waters into a Habitat Protection Zone (IUCN category IV) and two Sanctuary Zones (IUCN Category Ia) (National Heritage Trust 2002). In 2009 a re-zoning exercise was launched to define areas suitable for protection in line with the strategic objectives of the Park. In relation to this exercise, the mapping activities that are the focus of this case study draw on geospatial technology to address two basic and commonly arising questions in the field of marine conservation: "What is the spatial distribution of the marine seafloor habitats around Lord Howe Island?" and “Where should the marine reserve boundaries be located?" These questions were posed to a group of fifteen geospatial analysts, mostly comprised of postgraduate students in the School of Earth \& Environmental Sciences at the University of Wollongong. All of these students had received at least six months of formal training in the use of geospatial technology.

Each analyst was supplied with a collection of spatially referenced datasets containing information on both the physical and biological attributes of Lord Howe Island (see Table 1 for details of datasets) and requested to use the data provided in whatever way they saw appropriate to answer the questions posed. In answering the questions, each analyst was asked to provide a map outlining the suggested marine park boundaries, a methodology outlining the analysis underpinning the definition of these boundaries and an accompanying explanation of the overall park objectives and conservation management principles guiding the analysis.

\section{(see end of document)}

Table 1. Datasets provided to geospatial analysts in order to answer the questions: "What is the spatial distribution of the marine seafloor habitats around Lord Howe Island?" and "Where should the marine reserve boundaries be located?” 
Figure 1 illustrates the answers provided by the fifteen analysts who took part in the Lord Howe Island geospatial exercise. It can be seen that a wide range of responses were received to the questions posed, despite the fact that each analyst was presented with the same dataset.

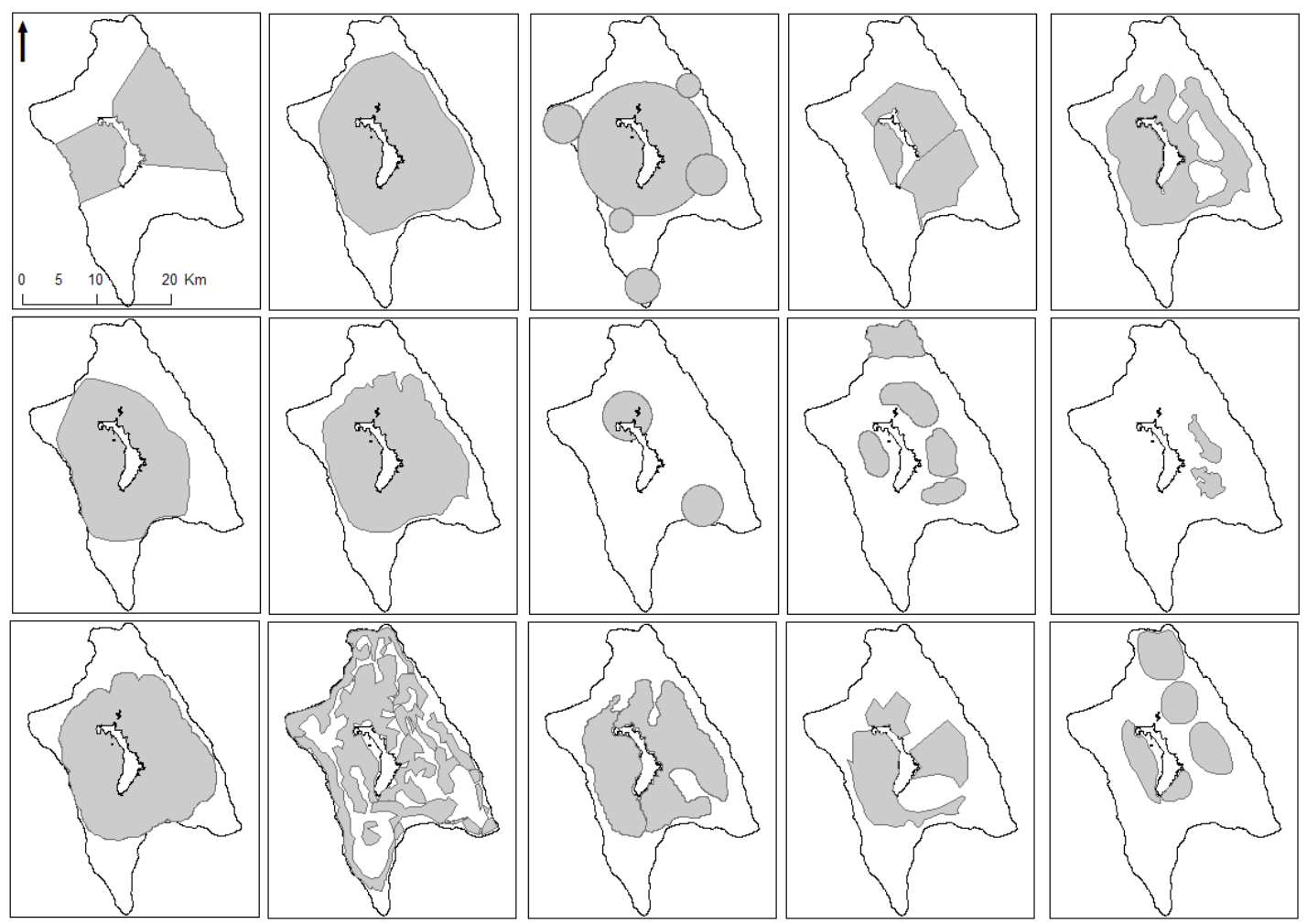

Figure 1 Marine reserve boundaries suggested by fifteen geospatial analysts, each provided with the same spatially referenced datasets on the physical and biological attributes of the seafloor around Lord Howe Island, NSW. Outer black boundary indicates the edge of the continental shelf platform, inner black boundary indicates the island periphery and the gray areas are the suggested marine reserves.

Figure 2 summarises broadly the different approaches employed by the analysts to answer the questions posed. In relation to the first question, some of the analysts chose to apply a standard image classification to some of the spatially continuous remote sensing datasets provided, while others chose to employ information from the field datasets provided to model biophysical relationships that could extrapolate existing biological information across larger areas. Nestled within both of these approaches were alternative techniques (e.g. supervised vs. unsupervised classification and ordinary least squares vs. spatial regression modelling) that were selected by the analysts. In relation to the second question, some of the analysts chose to delineate a suggested marine park boundary by visually assessing and then manually drawing a boundary, while others chose to employ spatial querying tools 
such as intersects, weighted combinations, buffers and overlays to generate a boundary. It can therefore be seen that a large number of different permutations are possible in terms of approaches to analysis undertaken. Depending on the decisions made by the analysts, the questions posed were therefore answered in a variety of manners.

\section{Question 1: Model and map benthic habitats around} Lord Howe Island based on the available information (Cartographic representation)

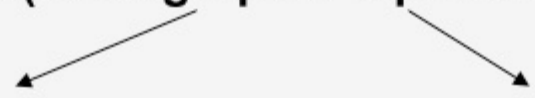

Image classification (40\%) Modelling (60\%)


Supervised Unsupervised OLS regression Spatial regression

\section{Question 2: Provide a recommendation to the Marine Parks} Authority on where the marine reserve boundaries should be located

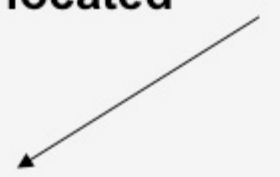

Visually assess results (35\%)



Manually digitise boundary

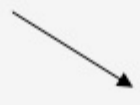

Apply criteria (65\%):

- Spatial intersect

- Weighted combination

- Buffer

- Overlay



\section{Generate boundary result}

Figure 2 A flow diagram illustrating the different approaches adopted by geospatial analysts to answer the questions posed, along with a breakdown of the proportion of analysts who selected each approach.

The suggested boundary of the marine park was highly inconsistent. Such inconsistencies translate into substantial implications for management of coastal resources, which in turn, give rise to the power of maps as instruments for influencing coastal management decision making. For example, the economic contribution of 
tourism, commercial fishing, cultural and recreational activity of the Great Barrier Reef Marine Park in 2005-06 was estimated at $\$ 6.9$ billion per Annum, which equates to an economic value of approximately $\$ 200 \mathrm{~K}$ per square $\mathrm{km}$ of reef area (Access Economics, 2007). In terms of coverage, the difference between the suggested park areas in the present exercise was 330 sq.km (the smallest marine park suggested was 20 sq.km, whereas the largest was 350 sq.km). This translated to an economic value of \$66 million per Annum.

Analytical support for managing marine parks draw on both socioeconomic drivers (e.g. for establishing park objectives) and biophysical information (e.g. for defining park boundaries). In relation to socioeconomic considerations, the spatial configuration of marine park boundaries has important implications for how coastal resources are used. For example, the existing Commonwealth Park boundaries at Lord Howe delineate a "Habitat Protection Zone", within which two "Sanctuary Zones" are further identified. A World Heritage Area has also been designated across these zones (Figure 3). In response to concerns about the potential impacts of large-scale commercial fishing on local fish stocks, trawling and other fishing methods were excluded from the Habitat Protection Zone in 1993 (Senate Standing Committee 1993). The two Sanctuary Zones are subject to Australian IUCN reserve management principles for strict nature reserves, which incorporate a complete ban on fishing within the zone by any method, as well as mining operations, including petroleum and mineral exploration and recovery. These Zones are managed exclusively for scientific research and environmental monitoring. Socioeconomic considerations, which are often informed through stakeholder consultation, are critical to the establishment of a democratic and effective marine park that is underpinned by widely held management objectives (Charles and Wilson, 2009). In relation to the establishment of park objectives, it is important to maintain an awareness of potential political subjectivities given the divergent values of different stakeholders, the high degree of scientific uncertainty and the high marine resource management decision stakes that often characterise marine conservation planning (Jones, 2002). Analysts' responses defined a wide range of park objectives, such as protecting rare and vulnerable habitats and species, conserving a representative set of habitat types, controlling tourism and recreation, promoting integrated coastal management and protecting areas of value for cultural heritage. 
In relation to biophysical considerations, the management of marine parks is often guided by conservation management principles that draw on scientific research. For example, the conservation management principles underpinning establishment of the Sanctuary Zones at Lord Howe were that they aimed to protect a representative sample of the shelf, slope and deepwater environment (National Heritage Trust 2002). While representativity is an important tenet of marine conservation and, by extension, protected area design (Stevens, 2002), possible alternative conservation management principles could have included criteria such as biogeographic representation, habitat representation and heterogeneity, the presence of species or populations of special interest (e.g., threatened species), the reserve size necessary to protect viable habitats, presence of exploitable species, vulnerable life stages, connectivity among reserves, links among ecosystems, and provision of ecosystem services to people (Roberts et al. 2003; Lourie and Vincent, 2004). Applied research at Lord Howe Island suggests that habitat may be a useful surrogate for fish diversity (Lindsay et al. 2008) and that deep sea biophysical variables such as seabed geomorphology, substratum type and depth are useful surrogates for biological assemblages (Anderson et al. 2005). An attempt to inform spatial analysis activities with published scientific research might itself, therefore, draw on a variety of guiding principles. This was reflected in the range of explanations provided by geospatial analysts, who drew on conservation management principles such as connectivity, endemism and naturalness.

The extent to which such practical outcomes are influenced by analytical decisionmaking is a contemporary manifestation of Harley’s internal cartographic power, as the varying messages conveyed by these maps are clearly determined by actions taken by the respective cartographer or geospatial analyst in the process of map production. This finding highlights the subjectivity of this scientific practice and brings to the fore the unexamined reductionist notion that investment in high accuracy and detailed, precise geospatial datasets moves us toward an objective truth. 


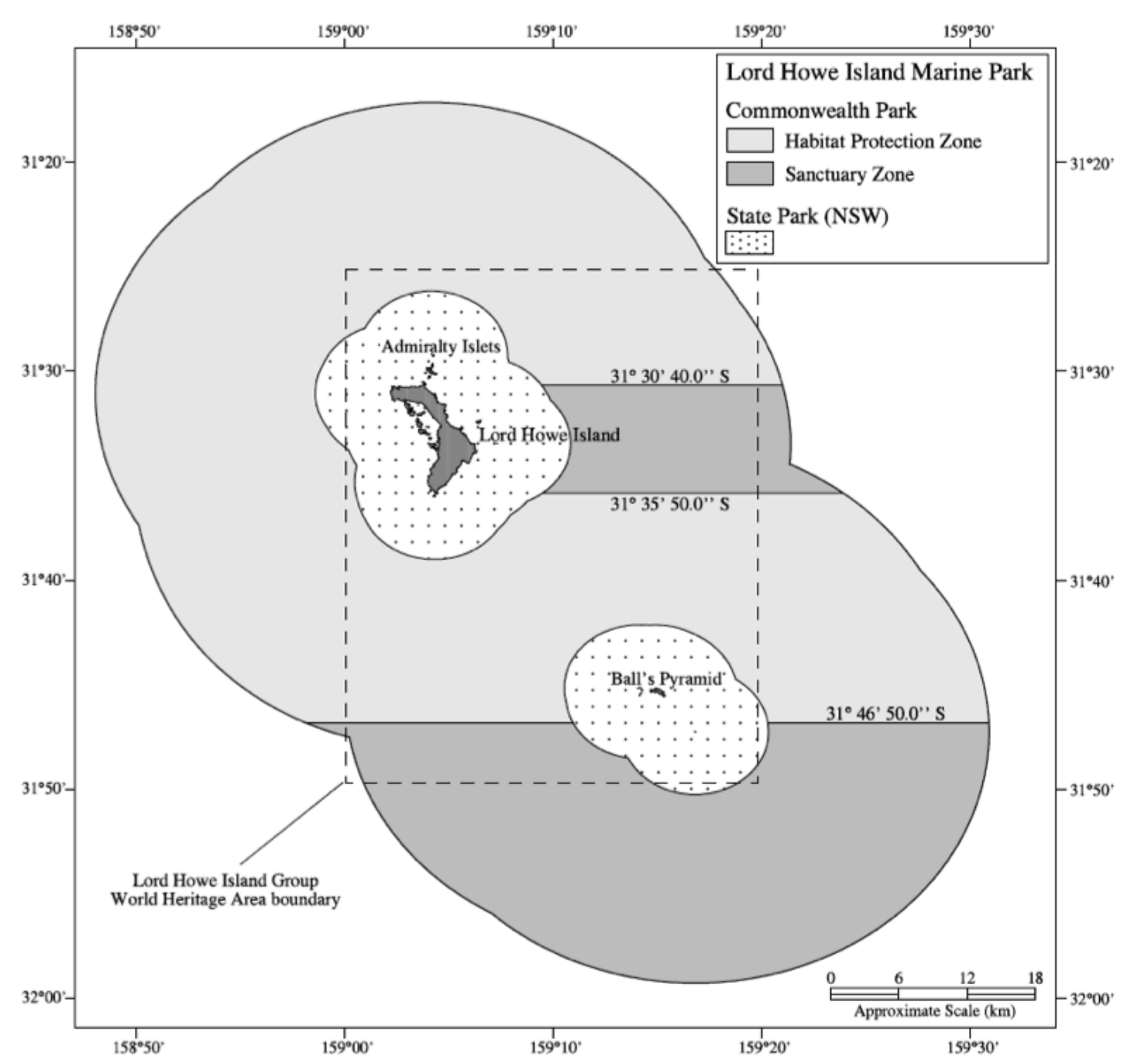

Figure 3. Lord Howe Island Marine Park Zones, including the Habitat Protection Zone, Sanctuary Zones and World Heritage Area. Source: Lord Howe Island Marine Park (Commonwealth Waters) Management Plan.

\section{$\underline{\text { Maps as subjective power: new technologies, perennial questions? }}$}

In this case study we see the subjectivities associated with cartographic campaigns, in relation to the motivations of analysts and the placement of boundaries in the scientific practice of cartography. Technology seems to be able to answer the pragmatic need to carry out an inventory of biodiversity in order to ensure its protection can be met with a wide variety of responses. Regardless of the technical specifications of geospatial datasets (for example, such campaigns may invest in improving accuracy, precision and resolution), the inconsistencies associated with the decisions that analysts make when working with these datasets prevent unification toward a 'cartographic truth'. This power of the cartographer is expanding with the 
increasing availability and affordability of geospatial information. For contemporary mapmakers, such as government national mapping agencies, topographic survey departments, conservationists and University Cartographic units, this message is important. It encourages a reading of maps as sources of information on socially constructed worlds as much as the physical world of objects. Far from reducing the importance of cartography in our understanding of place, this opens up a new range of possibilities that go beyond the two dimensional portrayal of landforms to explore how spatial representations are made, who makes them, and why. Such a reading is particularly important given the fast pace of adoption of mapping technologies by fields such as conservation. It uncovers new opportunities for retaining and growing our interest in cartography to discover meaning in maps and for tracing, through cartography, the social agendas of mapmakers and their patrons. As geographers, such a reading presents us with an opportunity to define, or redefine, our relation to the structures of knowledge and power that influence our understanding of place. Through this case study, I have elaborated on one of many examples I have seen as a geographical researcher and subjected this to the critical scrutiny it deserves with the hope of reminding people of the historical lineage of maps as subjective power - a lineage unbroken in the present day.

By reflecting on the two exploratory edges that provide the framework of the present study, geographers are encouraged to take a broader view and work at the edges of our discipline to address the research challenges of the twenty first century. In the case of mapping as a practice, this is manifest in the need to adopt both a positivist and a post-structuralist standpoint to fully appreciate the power of this quintessentially geographical activity. Geography is an inherently political pursuit grappling with the unruly spatial politics of race and nation, nature and culture, past and present (Stoddart, 1986). Scientific techniques have a lot to offer in terms of supporting practical objectives associated with pursuits such as conservation. But the methodological cutting edge demands that we do not accept uncritically the tools and techniques we use to understand and manage the environment, both in the application of geospatial technologies but also more broadly in the epistemological practice of geography.

\section{$\underline{\text { References }}$}


Access Economics Pty Ltd (2007) Measuring the economic and financial value of the Great Barrier Reef Marine Park, 2005-06. Research Publication N ${ }^{0} .88$, Great Barrier Reef Marine Park Authority, Townsville

Adams, W., Mulligan, M. (2003) Decolonizing Nature: Strategies for Conservation in a Post-colonial Era. Earthscan Publications Ltd, London.

Anderson, T.J., Nichol, S.L., Syms, C., Przeslawski, R., Harris, P.T. (2011) Deep-sea bio-physical variables as surrogates for biological assemblages, an example from the Lord Howe Rise. Deep Sea Research II, 58, 979-991.

Cameron, J. (2003) Responding to place in a post-colonial era: An Australian Perspective. In W. Adams, M.Mulligan (eds) Decolonizing Nature: Strategies for Conservation in a Post-colonial Era., pp.172-197. Earthscan Publications Ltd, London.

Charles, A., Wilson, L. (2009) Human dimensions of marine protected areas. Journal of Marine Science, 66, 6-15.

Couclelis, Helen. (2003) The Certainty of Uncertainty: GIS and the Limits of Geographic Knowledge. Transactions in GIS, 7, 165-175.

Crampton, J. W. (2001) Maps as Social constructions: power, communication and visualization. Progress in Human Geography, 25, 235-252.

Crampton, J. W. (2010) Mapping: A critical introduction to cartography and GIS. Wiley-Blackwell, Oxford.

Dodge, M., Kitchin, R., Perkins, C. (2011) The Map Reader: Theories of Mapping Practice and Cartographic Representation. John Wiley and Sons Ltd, Oxford.

Figgis, P. (2003) The changing face of nature conservation: Reflections on the Australian Experience. In W. Adams, M.Mulligan (eds) Decolonizing Nature: Strategies for Conservation in a Post-colonial Era., pp.197-220. Earthscan Publications Ltd, London.

Fischer, DH (2004) Washington's Crossing. Oxford Press, New York.

Foucault, M. (2000) So is it important to think? In: J.B. Faubion (ed), Power: The Essential works of Michel Foucault 1954-1984, Vol 3, pp.454-458. The New Press, New York.

Francis, M.P. (1993) Checklist of the coastal fishes of Lord Howe, Norfolk, and Kermadec Islands, Southwest Pacific Ocean. Pacific Science, 47, 136-170.

Gibson, C., Brennan-Horley, C., Warren, A. (2010) Geographic information technologies for cultural research: cultural mapping and the prospects of colliding epistemologies. Cultural Trends, 19, 325-348.

Harriott, V.J., Harrison, P.L., Banks, S.A. (1995) The coral communities of Lord Howe Island. Marine and Freshwater Research, 46, 457-465.

Harley, J.B. (1989) Deconstructing the map. Cartographica, 26, 1-20.

Harley, J.B. (1996) The New Nature of Maps: Essays in the History of Cartography. The John Hopkins University Press, Baltimore.

Harris, P.T. (2011) Benthic environments of the LordHowe Rise submarine plateau: Introduction to the special volume. Deep Sea Research Part II: Topical Studies in Oceanography, 58, 883-888. 
Howitt, R. (2002) A Geographer's Way of Seeing - geographical imaginaries and political realities. Interaction: Journal of the Geography Teachers' Association of Victoria, 30, 7-12.

Jacobs, J.M. (1996) Edge of Empire: Postcolonialism and the city. Routledge, London.

Jones, P.J.S (2002) Marine protected area strategies: issues, divergences and the search for middle ground, Reviews in Fish Biology and Fisheries, 11, 197-216.

Lindsay, M.J., Patterson, H.M., Swearer, S.E. (2008) Habitat as a surrogate measure of reef fish diversity in the zoning of the Lord Howe Island Marine Park, Australia, Marine Ecology Progress Series, 353, 265-273.

Lourie, S.A., Vincent, A. (2004) Using biogeography to help set priorities in marine conservation, Conservation Biology, 1, 1004-1020.

National Heritage Trust (2002) Lord Howe Island Marine Park (Commonwealth Waters) Management Plan. Environment Australia, Canberra.

S.L. Nichol, A.D. Heap, J. Daniell (2011) High resolution geomorphic map of a submerged marginal plateau, northern Lord Howe Rise, east Australian margin. Deep Sea Research II, 58, 889-898.

Pickles, J. (2006) On the social lives of maps and the politics of diagrams: a story of power, seduction, and disappearance. Area, 38, 347-50.

Roberts, C.M., Andelman, S., Branch, G., Bustamante, R., Castilla, J.C. (2003) Ecological criteria for evaluating candidate sites for marine reserves. Ecological Application,. 13, 199-214.

Rorty, R. (1980) Philosophy and the Mirror of Nature. Cambridge University Press, Cambridge.

Schuurman, N, Pratt, G. (2002) Care of the Subject: feminism and critiques of GIS. Gender, Place and Culture, 9, 291-299.

Senate Standing Committee on Industry, Science, Technology, Transport, Communications and Infrastructure (1993) Fisheries Reviewed. Commonwealth of Australia: Canberra.

Sheppard, E. (1993) Automated geography: what kind of geography for what kind of society? Professional Geographer, 45, 457-460.

Stevens, S. (2002) Rigor and Representativeness in Marine Protected Area Design. Coastal Management, 30, 237-248.

Stoddart, D.R. (1986) On Geography and its History. Basil Blackwell, Oxford.

Sui, D.Z. (2001) Terrae Incognitae and Limits of Computation: Whither GIScience? Computers, Environment and Urban Systems, 25, 529-533.

Sui, D.Z. (2004) GIS, Cartography, and the "Third Culture": Geographic Imaginations in the Computer Age. The Professional Geographer, 56, 62-72.

Tobler, W. R. (1959) Automation and cartography. Geographical Review, 49, 52634.

Wood, D., Fels, J. (1992) The Power of Maps. The Guilford Press, New York. 
Woodroffe, C.D., Kennedy, D.M. Brooke, B.P., Dickson, M.E. (2011)

Geomorphological Evolution of Lord Howe Island and Carbonate Production at the Latitudinal Limit to Reef Growth. Journal of Coastal Research, 22, 188-201 


\begin{tabular}{|c|c|}
\hline DATA LAYER & DESCRIPTION \\
\hline \multicolumn{2}{|r|}{ Spatially continuous remotely sensed image layers } \\
\hline Bathymetry & $\begin{array}{l}\text { A measure of water depth based on detailed bathymetric swath data that were collected on the R.V. Southern Surveyor in } 2008 \\
\text { using the vessel's Kongsberg Simrad EM300 multibeam echo sounder. Horizontal resolution was resolved at approximately } \pm \sim 4 \\
\mathrm{~m} \text { and vertical resolution, referenced to mean sea level, is } \pm \sim 0.2 \mathrm{~m} \text {. Raster resolution: } 100 \mathrm{~m} \text {. }\end{array}$ \\
\hline LHI_srtm & $\begin{array}{l}\text { Shuttle Radar Topographic Mission (SRTM) provides topography information above land areas. The horizontal resolution is } 3 \\
\text { minutes (approximately } 90 \mathrm{~m} \text { at the } \\
\text { Equator) and the vertical datum is mean sea level as determined by the WGS84 Earth Gravitational Model. }\end{array}$ \\
\hline Rugosity & A measure of the small scale variations in height of the seafloor \\
\hline Moran & A localised measure of the moran statistic for every raster cell location around Lord Howe Island (cell size 100m) \\
\hline Terrain variables & $\begin{array}{l}\text { Several terrain variables that were derived from the bathymetry / terrain mosaic that was generated in practical } 6 \text { including: } \\
\text { slope, BPI (fine and broad scale), mean, majority, standard deviation, variety (you derived additional layers independently). }\end{array}$ \\
\hline LHI_Air_photo_2011 & A three band (RGB) colour composite Air photo taken of Lord Howe island by the Land and Property Management Authority \\
\hline \multicolumn{2}{|r|}{ Discrete point shapefiles from field collected datasets } \\
\hline Images & $\begin{array}{l}\text { Spatially referenced underwater photographs that exemplify the following geomorphic units: Basin, channel, modern reef , outer } \\
\text { shelf, relic reef, rugose reef. }\end{array}$ \\
\hline GT_Habitats & A set of 40 "ground-truthing” points indicating the geomorphic class for 40 locations around Lord Howe island. \\
\hline Coral_points & $\begin{array}{l}\text { A point dataset identifying the cover of benthic coral reef for } 14 \text { point locations around Lord Howe Island, along with associated } \\
\text { measures of bathymetry, rugosity, variety and BPI. Used for the spatial prediction modelling of coral reef around LHI in Prac } 7 \text {. }\end{array}$ \\
\hline Protected_fish & A point dataset identifying the presence or absence of protected fish at 40 locations around Lord Howe Island. \\
\hline Tow_points & $\begin{array}{l}\text { A point dataset identifying the following biophysical attributes for } 21 \text { point locations around Lord Howe Island: Sand, coarse sand, } \\
\text { sand ripples, rubble, stone, rocks overall, bedock reef, algae, kelp, gorgonians, ascidians, solitary corals, sponges, starfish, urchins } \\
\text { with accompanying measures for bathymetry, rugosity, variety and BPI. }\end{array}$ \\
\hline Transects_geographic & 7 polyline locations of the benthic underwater video samples \\
\hline Grabs & A point dataset identifying the substrate characteristics for 82 point grab sample locations around Lord Howe Island \\
\hline Shoreline/ Islands & Polyline and polygon datasets indicating the extent of the terrestrial environment at Lord Howe island \\
\hline Tracks & Polyline file detailing the tracks taken by the RV Southern Surveyor on the 2008 Expedition \\
\hline AOI & Polygon detailing the spatial extent of the outer shelf edge upon which Lord Howe Island sits \\
\hline \multicolumn{2}{|r|}{ Marine reserve zones } \\
\hline
\end{tabular}

2 Table 1: Datasets provided to geospatial analysts in order to answer the questions: "What is the spatial distribution of the marine seafloor

3 habitats around Lord Howe Island?” and "Where should the marine reserve boundaries be located?” 